This paper is published as: Schunck, R., \& Rogge, B. G. (2010). Unemployment and its Association with Health-Relevant Actions. Investigating the Role of Time Perspective with German Census Data. International Journal of Public Health, 55(4), 271-278.

The final publication is available at www.springerlink.com

\title{
Unemployment and its association with health-relevant actions: investigating the role of time perspective with German census data
}

\author{
Reinhard Schunck, Benedikt G. Rogge
}

\begin{abstract}
Objective In this study, we seek to explain how unemployment is related to an increase in healthdamaging actions. A short time perspective, that is an orientation towards the present rather than the future, is hypothesised to account for this effect. The concept of time perspective is located within an action theoretical framework and the hypothesis is tested empirically. Methods We investigated the unemployed people's smoking behaviour and body-mass index (BMI) using German Microcensus data from 2003. Data from 77,766 respondents (88.60\% employed and $11.40 \%$ unemployed) were analysed. Multivariate regression analysis was applied to test our hypotheses. Results Unemployment is associated with a $46 \%$ higher probability to smoke and with a 0.37 unit increase in BMI compared to employment. The likelihood of smoking steadily increases with the duration of unemployment, while only unemployment spells of 4 years and longer are significantly related to BMI. Yet, the smoking probability of those unemployed who have a long time perspective is $74 \%$ lower and their BMI is 1.81 lower than those who do not have a long time perspective. Conclusion Unemployment is negatively associated with health-relevant actions. This effect varies according to persons' time perspectives. Our approach delivers an innovative view on why unemployed individuals exercise more health-damaging actions than the employed.
\end{abstract}

Keywords: Health behavior, Unemployment, Smoking, Obesity, Action theory, Time perspective

\section{INTRODUCTION}

Unemployment has been shown to negatively affect a number of health-related outcomes, such as subjective health, symptoms of depression and anxiety, and even mortality (McKee-Ryan et al. 2005; Murphy and Athanasou 1999; Paul and Moser 2006). As numerous longitudinal studies and meta analyses demonstrate unemployment has a considerable negative, causal impact on health (Burgard et al. 2007; McKee-Ryan et al. 2005; Murphy and Athanasou 1999; Paul and Moser 2006). Besides, as is well-known, many health conditions are caused by health-damaging behaviours such as substance use, alcohol consumption, smoking, overeating and a lack of physical exercise (Lynch et al. 1997).

In fact, unemployed individuals are also considerably more vulnerable to displaying healthdamaging behaviours than the employed. As previous longitudinal studies show, again, this association is to be understood as a causal effect of unemployment (Bartley et al. 1999; Falba et al. 2005; Gallo et al. 2001, 2005; Mossakowski 2008; Siegrist 1996). For instance, longitudinal studies from Britain and Sweden hint at a growth of problem drinking in unemployed men and of obesity in 
unemployed women (Laitinen et al. 2002; Wadsworth et al. 1999). A Finish panel study finds an impact of an individual's employment trajectory on weight and alcohol consumption (Virtanen et al. 2008). Likewise, a study from the US shows that the likelihood of heavy drinking raises due to unemployment and increases with the duration of unemployment (Mossakowski 2008). Finally, data from the American Health and Retirement Survey show that unemployment also provokes an increase in smoking intensity with current smokers and in the likelihood of relapse in former smokers (Falba et al. 2005; Gallo et al. 2001, 2005). Unemployment thus entails an intensification in the exercise of health-damaging behaviours, particularly among the long-term unemployed (Bartley et al. 1999).

Yet, previous studies fall short of providing a theoretical explanation to this association. In our view, the most pertinent framework to date is the effort-reward-imbalance model (ERI) (Siegrist 1996, 2000; Siegrist and Theorell 2006). In the ERI model, unemployment is seen as an individual's exclusion from the potentially rewarding social role of employment. This exclusion leads to a so called 'social reward deficiency' entailing stress reactions at the neuro-regulatory level. Unemployed individuals then rely upon health-damaging behaviours to compensate for the deficiency at this same level. What appears problematic in this conception is the direct link between stress, the consequential neuro-regulatory dysfunction and health-damaging behaviours. In this sense, a recent meta-analysis did not find any (direct) significant association between stress and health risk behaviours (Siegrist and Roedel 2006). As we argue, it is indispensable to include non-damaging health behaviours as potentially adequate means of compensating for stress. When responding to unemployment, individuals may well abstain from health-damaging behaviours. The specific question is why many people draw upon health-damaging rather than health-enhancing behaviours.

Dealing with this issue, we should like to emphasise one major tenet of current action theory: the acknowledgement of an individual's subjective perceptions of, and agency in, a given social situation (Giddens 1984; Udehn 2002). When attempting to explain differences in health behaviours, such as between employed and unemployed individuals, we argue for tracing them back to differences at the level of an individual's cognitions, emotions, and actions.

\section{THEORETICAL FRAMEWORK}

We use the notion of 'health-relevant action' rather than 'health behaviour,' thus accentuating that the experience of stress translates into health behaviours only through the involvement of individual actors. This also implies that individuals potentially handle their health-relevant actions in a reflexive way and may even deliberately change them, for example, when deciding to diet, starting to play football or choosing to work as a volunteer (Thoits 2006). Obviously, features of the social context and the social structure do play a significant role in this process, be it in the form of unequally distributed economic, social or cultural resources (Abel, 2008).

Regarding our research question, we concentrate on the temporal dimension of action that has often been accentuated in action theory (Boudon 1980; Emirbayer and Mische 1998; Flaherty 2002). Specifically, we look at an actor's 'time perspective' that is the extent to which an actor is oriented towards future, past or present events and trajectories of action (Henson et al. 2006). Time perspective is stated to affect cognitive, emotional and behavioural outcomes (Zimbardo and Boyd 1999). In our conception, time perspective is a dynamic construct amenable to changes as one's life conditions are transformed through life events. A particular occasion for stressing the relevance of time perspective for us is its prominent position in unemployment research. Unemployment has often been stated to provoke a shift from an orientation towards the future to an orientation towards the present (Fagan et al. 2007; Montgomery et al. 1998; Tismer 1985). Many studies found that unemployment leads to an erosion of biographical plans, an abandonment of the future and a loss of hope. Yet, which role time perspective plays in unemployed individuals' health-relevant actions has never been investigated. We 
suggest that the concept of time perspective is crucial for understanding health-relevant actions in unemployment.

Backing up this argument, social psychologists have shown that a short time perspective is associated with the pursuit of emotionally meaningful goals, that are "goals related to feelings, such as balancing emotional states," while a long time perspective and an orientation towards the future relate to the pursuit of "expansive goals, such as acquiring knowledge or making new social contacts", (Carstensen et al. 2003). While expansive goals, such as educational goals, require continuous investment, and their related rewards are realised only in the long run, emotionally meaningful goals relate to more immediate, short term outcomes. In effect, a variety of health-damaging actions are apt to fulfil the function of regulating emotions. Social psychological studies therefore report an association of a reduced time perspective with adverse health actions such as smoking or alcohol and substance abuse (Keough et al. 1999; Zimbardo and Boyd 1999).

Concluding from these remarks, we assume that the increase in health-damaging actions during unemployment goes not only back to an increased perception of distress and the need to reduce this distress. It is also explained through an actor's time perspective. First, a short time perspective increases the likelihood to strive for short-term rewards which health-damaging actions may provide. Second, a short time perspective leads to an underestimation of long-term consequences of action including both the negative effects of health-damaging action and the positive effects of, for instance, educational investment (Boudon 1980). Consequently, the probability of health-damaging actions, such as excessive eating and smoking, increases. Our conception is summed up in Fig. 1.

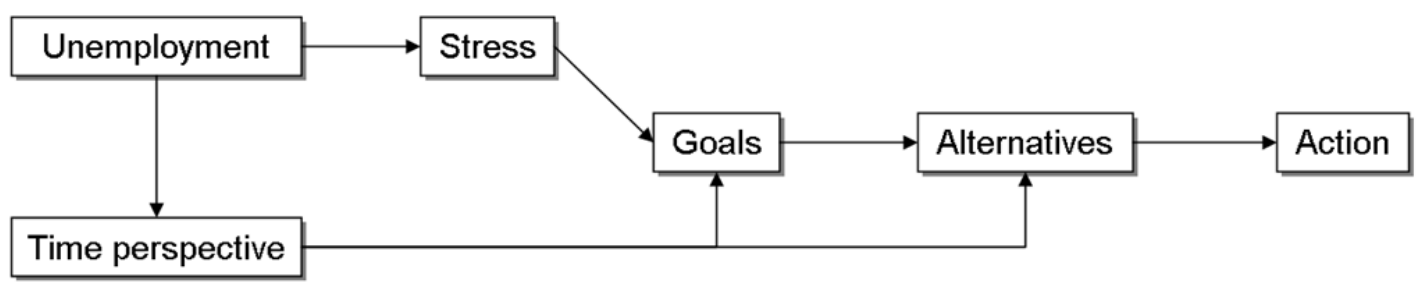

Fig. 1 Graphical portrayal of the association of unemployment, time perspective, psychosocial stress and health-relevant action

Finally, in line with previous research, we assume that the impact of unemployment on health-relevant actions increases with time. The longer an individual is unemployed, the more health-damaging actions will he/she exercise. Health scholars hint at a potential chronic dimension of strain with time that may lead to exacerbated health consequences (Aneshensel 1999; Pearlin 1999). In this sense, long-term unemployment can produce a feeling of 'entrapment' (Brown, 2005), and there is empirical evidence that the long-term unemployed show more health-damaging actions than the short-term unemployed (Grobe and Schwartz 2003).

\section{Hypotheses}

From this, we derive the following hypotheses: unemployment is associated with a higher probability of health-damaging actions (Hypothesis 1a). Moreover, the longer an individual is unemployed the higher is the probability that he/she exercises health-damaging actions (Hypothesis 1b). However, the way an individual responds to the experience of stress depends on his/her time perspective: a long time perspective is associated with a lower probability of health-damaging actions (Hypothesis 2). 


\section{METHODS}

\section{Data}

The empirical analysis of our study is based on German census data (Microcensus). The Microcensus is an annual, representative 1\% sample of the German population. Since it is a household based survey, information on all household members is collected. A scientific use file, which is a $70 \%$ subsample of the original Microcensus, is available for scientific analysis. A unique feature of the Microcensus is that participation is compulsory. Refusing to take part in this survey is considered an administrative offence, resulting in response rates of $97 \%$ and higher. The micro-census contains mainly demographic information, such as labour market participation, income, etc. In 4-year cycles additional information on special topics is collected for a subsample, which included in 2003 information on health, among other things on smoking, weight and height.

We restrict our analysis to employed and unemployed respondents who are of 15 years and older. Non-working, non-unemployed respondents, such as house-keepers or pensioners, are thus excluded from the analysis. Overall 77,766 cases enter the multivariate analysis (descriptive statistics are reported in Table 1).

\section{Measurement and variables}

Our first dependent variable is smoking, a binary variable indicating whether a respondent reports being a current smoker. The second dependent variable is a person's body mass index (BMI), calculated from self-reported weight and height. We use the BMI as an indicator for a person's diet and physical exercise.

As independent variables we include employment status (unemployed versus employed) and duration of unemployment. Unemployment duration is measured by five dichotomous indicators: Short-term unemployment is measured as: 1-5 months of unemployment and 6-11 months, long-term unemployment as $1-2$ years, $2-4$ years, 4 years and more.

Previous scholars who researched time perspective have operationalised this concept by measuring to what extent people plan their lives ahead, do things impulsively and the like (see, e.g., item formulations in the Zimbardo Time Perspective Inventory (Zimbardo and Boyd 1999)). Since the Microcensus does not contain any direct operationalisation of time perspective, we used a proxy. Drawing on the sociological and social-psychological researchers mentioned earlier, we regard time perspective as a latent concept that is reflected in manifest indicators, amongst them behavioural ones. Specifically, we used educational investment as a manifest indicator for a long time perspective, that is an orientation towards the future. In fact, a number of prominent sociological scholars assume that educational investment is the prototypical example of an expansive goal, since it requires a person to adopt a long time perspective (Boudon 1980; Carstensen et al. 2003). More precisely, we used information on whether during the 4 weeks preceding the interview, a person has participated or is participating in further educational training, advanced training, or extension studies. The Microcensus differentiates between educational trainings for occupational and for private reasons. Educational training for occupational reasons during unemployment might often be induced by employment agencies and might therefore not be voluntary. Hence, educational investment for occupational reasons does not constitute a valid indicator for a person's time perspective. We thus focus on the participation in voluntary educational programs.

To control for unobserved heterogeneity, we furthermore included into the analysis the respondents' sex, age, citizenship, education (CASMIN classification), net income, household net income, marital status, number of persons in the household, residency (East-or West-Germany), and 
hours of the respective educational investment. Descriptive statistics of the major variables can be found in Table 1.

We computed two models for smoking as well as the BMI. The first model compares unemployed with employed respondents. The second model includes only unemployed respondents, with 1 to 5 months of unemployment serving as the reference category.

Table 1 Socioeconomic characteristics, body-mass index, and smoking status for employed and unemployed respondents of the 2003 German Microcensus

\begin{tabular}{|c|c|c|c|c|c|}
\hline \multirow[b]{2}{*}{ Variable } & \multicolumn{3}{|c|}{$\begin{array}{l}\text { Employed and Unemployed } \\
\qquad(\mathrm{N}=77,766)\end{array}$} & \multicolumn{2}{|c|}{$\begin{array}{l}\text { Unemployed } \\
(\mathrm{N}=8,345)\end{array}$} \\
\hline & Mean/\% & & SD & Mean/\% & SD \\
\hline Sex (male) & 54.77 & $\%$ & & 55.61 & $\%$ \\
\hline Age & 40.46 & & 11.95 & 41.13 & 12.38 \\
\hline BMI & 24.97 & & 4.13 & 25.69 & 4.75 \\
\hline Smoking & 37.21 & $\%$ & & 50.09 & $\%$ \\
\hline Unemployed & 11.40 & $\%$ & & & \\
\hline Duration of unemployment (month) & & & & 20.46 & 17.34 \\
\hline Educational investment (occupational) & 3.15 & $\%$ & & 2.91 & $\%$ \\
\hline Educational investment (private) & 0.46 & $\%$ & & 0.56 & $\%$ \\
\hline Net income & 1430.15 & & 1269.44 & 607.37 & 429.09 \\
\hline \multicolumn{6}{|l|}{ Education } \\
\hline Inadequately completed general education & 1.60 & $\%$ & & 3.80 & $\%$ \\
\hline General elementary education & 7.86 & $\%$ & & 14.44 & $\%$ \\
\hline Basic vocational qualification & 25.53 & $\%$ & & 26.42 & $\%$ \\
\hline Intermediate general qualification & 2.50 & $\%$ & & 4.22 & $\%$ \\
\hline Intermediate vocational qualification & 31.21 & $\%$ & & 33.89 & $\%$ \\
\hline General maturity & 1.56 & $\%$ & & 1.68 & $\%$ \\
\hline Vocational maturity & 7.94 & $\%$ & & 4.52 & $\%$ \\
\hline Lower tertiary education & 4.83 & $\%$ & & 2.86 & $\%$ \\
\hline Higher tertiary education & 8.97 & $\%$ & & 3.57 & $\%$ \\
\hline In school & 7.00 & $\%$ & & 3.59 & $\%$ \\
\hline
\end{tabular}

Source: Microcensus 2003, own computations, number of cases based on multivariate models.

\section{Estimation method}

We estimated linear regression models for the BMI and logistic regression models for smoking. All estimates are based on robust standard errors, to correct for clustering in households (Long and Freese 2001). Stata 10 was used for analysis.

\section{RESULTS}

The composition of the sample is summarised in Table 1 . At the time of the interview, $11 \%$ of the 77,766 respondents were unemployed, with an average unemployment duration of 20 months. When looking at the indicators of health actions, we find the expected pattern: on average, unemployed respondents have a higher BMI (25.69) than employed respondents (24.97) and the share of smokers is also larger in the unemployed (50.09\%) than in the employed (37.21\%). 
However, since we know that several dimensions of socioeconomic status are associated with a person's BMI and smoking probability, it is necessary to compute multivariate models to test our hypothesis. Two different models were computed for both dependent variables: One model comparing employed and unemployed respondents and one model for unemployed respondents only.

With regard to smoking we find support for our hypothesis. Controlling for the other variables, unemployment is associated with an increased probability of being a smoker (Table 2). The odds of smoking are 54\% higher for unemployed respondents compared to employed respondents.

Table 2 Adjusted odds ratios estimates of smoking likelihood among respondents of the 2003 German Microcensus

\begin{tabular}{|c|c|c|c|c|}
\hline \multirow[t]{2}{*}{ Variable } & \multicolumn{2}{|c|}{$\begin{array}{c}\text { Model 1: } \\
\text { Employed and unemployed }\end{array}$} & \multicolumn{2}{|c|}{$\begin{array}{c}\text { Model 2: } \\
\text { Unemployed }\end{array}$} \\
\hline & OR & 95\% C. I. & OR & 95\% C. I. \\
\hline Employed & Reference & & & \\
\hline Unemployed & $1.53 * * *$ & $\left(\begin{array}{ll}1.46 & 1.60\end{array}\right)$ & & \\
\hline No educational investment & Reference & & Reference & \\
\hline Educational investment (occupational) & 0.91 & $\left(\begin{array}{ll}0.81 & 1.02\end{array}\right)$ & 0.90 & $\left(\begin{array}{ll}0.56 & 1.44\end{array}\right)$ \\
\hline Educational investment (private) & $0.55 * * *$ & $\left(\begin{array}{ll}0.40 & 0.75\end{array}\right)$ & $0.26 * *$ & $\left(\begin{array}{ll}0.11 & 0.63\end{array}\right)$ \\
\hline Unemployed: 1 to 5 months & & & Reference & \\
\hline Unemployed: 6 to 11 months & & & 1.11 & $\left(\begin{array}{ll}0.97 & 1.28\end{array}\right)$ \\
\hline Unemployed: 1 up to 2 years & & & $1.16 *$ & $\left(\begin{array}{ll}1.00 & 1.34\end{array}\right)$ \\
\hline Unemployed: 2 up to 4 years & & & $1.22 * *$ & (1.05 1.42) \\
\hline Unemployed: 4 years and longer & & & $1.54 * * *$ & (1.32 1.79$)$ \\
\hline Constant $^{\mathrm{a}}$ & 0.07 & $\left(\begin{array}{ll}-0.15 & 0.30\end{array}\right)$ & -0.80 & $\left(\begin{array}{ll}-0.68 & 0.52\end{array}\right)$ \\
\hline No. Obs. & 77,766 & & 8,345 & \\
\hline McKelvey \& Zavoina $\mathrm{R}^{2}$ & 0.12 & & 0.19 & \\
\hline
\end{tabular}

Source: Microcensus 2003, own computations, confidence intervals in parenthesis, estimation based on robust standard errors. Models are adjusted for age, age2, sex, citizenship, education (CASMIN), marital status, net income, household netincome, region (East- or West-Germany).

$* * *, * *, *$ Significance at the $0.1,1$, and 5 percent levels.

${ }^{\mathrm{a}}$ These constants are the log odds.

When examining only those respondents who are unemployed, we observe an increasing association between the duration of unemployment and smoking. Compared to the reference category, that is being unemployed for 1-5 months, there is no significant difference in the smoking likelihood for respondents who are unemployed for 6-11 months. However, compared to the reference category, respondents who are unemployed for 1 up to 2 years are significantly more likely to smoke. Their odds of smoking increase by $16 \%$. The odds of smoking for those respondents who are unemployed 2 up to 4 years are increased by $22 \%$. Eventually, the odds of smoking are increased by $54 \%$ for respondents who are unemployed for 4 years and more. It is noteworthy that not only the odds ratios become larger, but also the level of significance increases. These findings are thus consistent with the specification of our first hypotheses (1a and $1 \mathrm{~b}$ ). With regard to time perspective, we find that investing into education significantly reduces the odds of being a smoker by $73 \%$. This result is line with our second hypothesis. 
Table 3 Adjusted parameter estimates of linear regression on body-mass index among respondents of the 2003 German Microcensus

\begin{tabular}{|c|c|c|c|c|}
\hline \multirow[t]{2}{*}{ Variable } & \multicolumn{2}{|c|}{$\begin{array}{c}\text { Model 1: } \\
\text { Employed and unemployed }\end{array}$} & \multicolumn{2}{|c|}{$\begin{array}{l}\text { Model 2: } \\
\text { Unemployed }\end{array}$} \\
\hline & $\mathrm{b}$ & $\mathrm{t}$ & b & $\mathrm{t}$ \\
\hline Employed & Reference & & & \\
\hline Unemployed & $0.37 * * *$ & (7.93) & & \\
\hline No educational investment & Reference & & Reference & \\
\hline Educational investment (occupational) & 0.19 & $(1.87)$ & -0.26 & $(-0.60)$ \\
\hline Educational investment (private) & $-0.65 * *$ & $(-2.98)$ & $-1.81 *$ & $(-2.22)$ \\
\hline Unemployed: 1 to 5 months & & & Reference & \\
\hline Unemployed: 6 to 11 months & & & 0.24 & $(1.58)$ \\
\hline Unemployed: 1 up to 2 years & & & 0.11 & $(0.74)$ \\
\hline Unemployed: 2 up to 4 years & & & 0.03 & $(0.18)$ \\
\hline Unemployed: 4 years and longer & & & $0.36 *$ & (2.15) \\
\hline Constant & $19.32 * * *$ & $(109.30)$ & $17.18 * * *$ & (30.89) \\
\hline No. Obs. & 77,766 & & 8,345 & \\
\hline $\mathrm{R}^{2}$ & 0.15 & 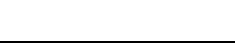 & 0.12 & \\
\hline
\end{tabular}

When it comes to the BMI, we find partial support for our hypothesis. Ordinary least squares regression shows that even when socioeconomic and demographic characteristics are being controlled for, unemployment is significantly related to a respondent's BMI (see Table 3). Controlling for the other variables in the model, being unemployed is associated with an increase of 0.37 units in a person's BMI compared to employed respondents (Table 3). Looking at the unemployed respondents, we find that only being unemployed for 4 years and more is significantly associated with a person's BMI. Respondents who are unemployed for 4 years and longer have on average a BMI which is 0.36 units higher compared to the reference category (1-5 months of unemployment). With regard to time perspective, the results confirm our hypothesis-educational investment for private reasons is significantly associated with a 1.81 decrease in the BMI compared to those respondents who do not invest into education.

It is worth mentioning that the effect of voluntary educational investments is not limited to unemployed respondents. In all four models this type of educational investments is significantly associated with a decreased probability of exerting health-damaging actions.

\section{Discussion}

As our investigation of German census data shows, unemployment is significantly associated with an increase in an individual's risk of exercising health-damaging actions: unemployed respondents have a higher BMI as well as a higher probability of smoking compared to those employed (Hypothesis 1a). Moreover, the longer an individual is unemployed, the higher is the likelihood of being a smoker. With regard to BMI, we only observed an increased association for people who are unemployed for 4 
years and longer (Hypothesis 1b). Our first hypotheses are thus supported. These results are largely consistent with previous studies. They not only link up with research on the effects of unemployment as reported earlier (Fagan et al. 2007; Falba et al. 2005; Gallo et al. 2005; Montgomery et al. 1998; Mossakowski 2008; Virtanen et al. 2008), but more specifically, they confirm the increased vulnerability to health-damaging actions among the long-term unemployed, as stated in other studies (Grobe and Schwartz 2003). In our study, this particularly applies to people being unemployed for longer than 4 years.

What is new about our study, however, is that it proposes and tests a novel assumption on the mechanism behind this association. In doing so, it goes beyond previous stress theoretical models. We hypothesised that the negative effect of unemployment operates through a shortening of an individual's time perspective. This leads to an increase in actions that aim at balancing emotional states in the short run, including health-damaging actions. In our empirical analysis, we found that among those who are unemployed, respondents who invest in education, displaying some orientation towards the future, are less likely to engage in health-damaging actions than those who do not. These findings prevail after statistically controlling for potential confounding factors such as income, education and marital status. We therefore also found support for our second hypothesis.

However, there is need for some reflection on the concept of time perspective. As argued earlier, we strongly believe that time perspective plays a crucial role in the unemployed people's health actions. Yet, one remaining question is whether unemployment effectively changes people's time perspectives, for instance by eroding bio-graphical plans and thus contracting the time perspective. Alternatively, variations in future outlooks may already exist before the emergence of the critical life event. We cannot answer this question in the present study due to the cross-sectional character of the data. In effect, we think both scenarios or a combination of them are possible. On the one hand, time perspectives are unequally distributed across social strata with people of lower social status being more likely to have short time perspectives (Tismer 1985). As additional analyses not provided here show, respondents with higher socio-economic status and higher educational degrees are more likely to invest into further education be it for private or occupational reasons (see also Hubert and Wolf 2007). On the other hand, it still seems convincing to assume a shift in an individual's time perspective due to job loss. People might have been fatalistic or pessimistic or engulfed by the present before job loss just as well as they might become following it. Note, however, that the majority of unemployment studies sug-gests the latter (Heinemeier 1991; Jahoda et al. 1933/1975). This issue relates to the question of whether time perceptive is to be understood as a stable personality construct (Zimbardo and Boyd 1999) or as a dynamic, situation-bound perspective.

However, only longitudinal investigations will be able to adequately answer these questions.

This takes us to the limitations of our study. Clearly, due to its cross-sectional nature, we cannot disentangle causal effects from (self-) selection effects (Morgan and Winship 2007). However, we think the findings in previous research deliver a solid basis for our argument. Moreover, we see one of our study's strengths in its theoretical contribution. The point of our study is actually to contribute to further illuminating the mechanisms behind the deleterious effects of unemployment. This notwithstanding, future studies need to test the hypothesised assumptions with longitudinal data.

Another limitation could be seen in the operationalisation of time perspective that we used. Including a direct measurement of time perspective, for instance, with such items as in the Zimbardo Time Inventory (Zimbardo and Boyd 1999), would obviously provide a stronger test of our theoretical assumptions. However, in line with the above-mentioned sociological and social psychological scholars, we believe that educational investment does represent a valid indicator, in fact a prototypical example, of a future-oriented action goal.

We have located the concept of time perspective within an action theoretical framework that looks at social disparities and temporal changes in an individual's perceptions, motivations and actions 
(Cockerham 2005; Thoits 2006). We think future sociology of health research will profit from taking into account such factors to a growing extent. It seems to us that the general task of deciphering the mechanisms of health disparities (Adler and Ostrove 1999) with regard to health behaviours implies looking closely at the level of individual action (Lindbladh and Lyttkens 2002).

Future studies on health-relevant action should include direct measurements of time perspective, draw on longitudinal data, further investigate dynamic changes over time such as caused by other critical life events (e.g. divorce, widowhood, death of a child), and also explore the role of the proximate social context (e.g. health action patterns of significant others) (Christakis and Fowler 2007, 2008). Including motivational and actional parameters in these studies will help to address this issue and deepen our understanding of the mechanisms lying behind the reproduction, and the potential change, of health inequalities.

Acknowledgments We would like to thank two anonymous reviewers as well as Nico Dragano, Moira Nelson, and Chris Swader for very helpful comments and advices. 


\section{REFERENCES}

Abel T (2008) Cultural capital and social inequality in health. J Epidemiol and Community Health 62(7):13

Adler NE, Ostrove JM (1999) Socioeconomic status and health: what we know and what we don't. In: Adler NE (ed) Socioeconomic status and health in industrial nations, vol 896, pp 3-15

Aneshensel CS (1999) Outcomes of the stress process. In: Horwitz AV, Scheid TL (eds) A handbook for the study of mental health. University Press, Cambridge, pp 211-227

Bartley M, Ferrie J, Montgomery S (1999) Living in a high unemployment economy: understanding the consequences. In: Marmot MG, Wilkinson RG (eds) Social determinants of health. Oxford University Press, Oxford, pp 81-104

Boudon R (1980) Die Logik des gesellschaftlichen Handelns. Eine Einfu“hrung in die soziologische Denk-und Arbeitsweise. Luchterhand, Neuwied

Brown GW (2005) The social origins of depression and the role of meaning. In: Heath A, Ermisch J, Gallie D (eds) Understanding social change. Oxford University Press, Oxford, pp 255-290

Burgard SA, Brand JE, House JS (2007) Toward a better estimation of the effect of job loss on health. J Health Soc Behav 48:369-384

Carstensen LL, Fung HH, Charles ST (2003) Socioemotional selectivity theory and the regulation of emotion in the second half of life. Motiv Emotion 27:103-123

Christakis NA, Fowler JH (2007) The spread of obesity in a large social network over 32 years. New Engl J Med 357:370-379

Christakis NA, Fowler JH (2008) The collective dynamics of smoking in a large social network. New Engl J Med 358:2249-2258 Cockerham WC (2005) Health lifestyle theory and the convergence of agency and structure. J Health Soc Behav 46:51-67 Emirbayer M, Mische A (1998) What is agency? Am J Sociol 103:962-1023

Fagan P, Shavers V, Lawrence D, Gibson JT, Ponder P (2007) Cigarette smoking and quitting behaviors among unemployed adults in the United States. Nicotine Tob Res 9:241-248

Falba T, Teng HM, Sindelar JL, Gallo WT (2005) The effect of involuntary job loss on smoking intensity and relapse. Addiction 100:1330-1339

Flaherty MG (2002) Making time: agency and the construction of temporal experience. Symb Interact 25:379-388

Gallo WT, Bradley EH, Siegel M, Kasl SV (2001) The impact of involuntary job loss on subsequent alcohol consumption by older workers: findings from the health and retirement survey. J Gerontol B Psychol Sci Soc Sci 56:S3-S9

Gallo WT, Teng H, Sindelar J, Falba T (2005) Effect of involuntary job loss on smoking intensity and relapse among older workers. Gerontologist 45:157

Giddens A (1984) The constitution of society: outline of the theory of structuration. Polity Press, Cambridge

Grobe TG, Schwartz FW (2003) Arbeitslosigkeit und Gesundheit. Robert-Koch-Institut, Berlin Heinemeier S (1991) Zeitstrukturkrisen. Biographische Interviews mit Arbeitslosen. Leske ? Budrich, Opladen

Henson JM, Carey MP, Carey KB, Maisto SA (2006) Associations among health behaviors and time perspective in young adults: Model testing with boot-strapping replication. J Behav Med 29:127-137 Hubert T, Wolf C (2007) Determinanten der beruflichen Weiterbildung Erwerbsta"tiger. Empirische Analysen auf der Basis des Mikrozensus 2003. Zeitschrift für Soziologie 36:473-493

Jahoda M, Lazarsfeld PF, Zeisel H (1933/1975) Die Arbeitslosen von Marienthal. Suhrkamp, Frankfurt a.M 
Keough KA, Zimbardo PG, Boyd JN (1999) Who’s smoking, drinking, and using drugs? Time perspective as a predictor of substance use. Basic Appl Soc Psych 21:149-164

Laitinen J, Power C, Ek E, Sovio U, Jarvelin MR (2002) Unemployment and obesity among young adults in a northern Finland 1966 birth cohort. Int J Obes 26:1329-1338

Lindbladh E, Lyttkens CH (2002) Habit versus choice: the process of decision-makingin health-related behaviour. Soc Sci Med 55:451-465

Long SJ, Freese J (2001) Regression models for categorical dependent variables using stata. Stata Press, Texas

Lynch JW, Kaplan GA, Salonen JT (1997) Why do poor people behave poorly? Variation in adult health behaviours and psychosocial characteristics by stages of the socioeconomic lifecourse. Soc Sci Med 44:809-819

McKee-Ryan FM, Song ZL, Wanberg CR, Kinicki AJ (2005) Psychological and physical well-being during unemployment: A meta-analytic study. J Appl Psychol 90:53-76

Montgomery SM, Cook DG, Bartley MJ, Wadsworth MEJ (1998) Unemployment, cigarette smoking, alcohol consumption and body weight in young British men. Eur J Public Health 8:21-27

Morgan SL, Winship C (2007) Counterfactuals and causal inference: methods and principles for social research. Cambridge University Press, New York

Mossakowski KN (2008) Is the duration of poverty and unemployment a risk factor for heavy

drinking? Soc Sci Med 67:947-955

Murphy GC, Athanasou JA (1999) The effect of unemployment on mental health. J Occup Organ

Psychol 72:83-99

Paul K, Moser K (2006) Quantitative reviews in psychological unemployment research: an overview.

In: Kieselbach T, Wine-field AH, Boyd C, Anderson S (eds) Unemployment and health international and interdisciplinary perspectives. Australian Aca-demic Press, Bowen Hill, pp 51-59

Pearlin LI (1999) The stress process revisited: reflections on concepts and their interrelationships. In:

Aneshensel CS, Phelan J (eds)

Handbook of the sociology of mental health. Plenum, New York, pp 395-416

Siegrist J (1996) Adverse health effects of high effort-low reward conditions at work. J Occup Health Psychol 1:27-43

Siegrist J (2000) Place, social exchange and health: proposed sociological framework. Soc Sci Med 51:1283-1293

Siegrist J, Roedel A (2006) Work stress and health risk behavior. Scand J Work Environ Health 32:473-481

Siegrist J, Theorell T (2006) Socioeconomic position and health: the role of work and employment. In: Siegrist J, Marmot M (eds) Social inequalities in health: new evidence and policy implica-tions.

Oxford University Press, Oxford, pp 73-100

Thoits PA (2006) Personal agency in the stress process. J Health Soc Behav 47:309-323

Tismer KG (1985) Time perspective and social-stratification. Kolner Z Soz Sozialpsychol 37:677-697

Udehn L (2002) The changing face of methodological individualism. Annu Rev Sociol 28:479-507

Virtanen P, Vahtera J, Broms U, Sillanmaeki L, Kivimaeki M, Koskenvuo M (2008) Employment trajectory as determinant of change in health-related lifestyle: the prospective HeSSup study. Eur J Public Health 18:504-508

Wadsworth MEJ, Montgomery SM, Bartley MJ (1999) The persisting effect of unemployment on health and social well-being in men early in working life. Soc Sci Med 48:1491-1499 Zimbardo PG, Boyd JN (1999) Putting time in perspective: a valid, reliable individual-differences metric. J Pers Soc Psychol 77:1271-1288 